\title{
An Assessment of the Adaptability to Climate Change of Commercially Available Maize Varieties in Zimbabwe
}

\author{
Tinashe Nyabako \\ Department of Soil Science and Agricultural Engineering \\ Faculty of Agriculture, University of Zimbabwe \\ PO Box MP 167, Mt Pleasant, Harare, Zimbabwe \\ Tel: 263-733-331-309 E-mail: tnyabako@gmail.com \\ Emmanuel Manzungu (Corresponding author) \\ Department of Soil Science and Agricultural Engineering \\ Faculty of Agriculture, University of Zimbabwe \\ PO Box MP 167, Mt Pleasant, Harare, Zimbabwe \\ Tel: 263-772-254-231 E-mail: manzungu@mweb.co.zw
}

\author{
Received: November 26, $2011 \quad$ Accepted: December 24, $2011 \quad$ Published: March 1, 2012 \\ doi:10.5539/enrr.v2n1p32 \\ URL: http://dx.doi.org/10.5539/enrr.v2n1p32
}

\begin{abstract}
A study was undertaken to assess the adaptability to climate change of commercially available maize varieties in Zimbabwe using 2010, 2020, 2050 and 2080 climate change scenarios. The FAO's Ecocrop Model was used to assess the suitability of early, short, medium and long season maize varieties grown under rainfed conditions in different agro-ecological regions ( 1 to 5 ) whose agricultural potential decreases progressively due to the amount of rainfall received. Regions 1 and 2 conditions are projected to decrease in size by $14 \%$, region 3 by $26 \%$, while regions 4 and 5 are projected to increase by $40 \%$. The area suitable for growing early low yielding maize varieties will remain at nearly $100 \%$ in regions 1 and 2 . The area suitable for growing medium maturing varieties will decline to below $20 \%$ in regions 4 and 5. Overall, only $2 \%$ of Zimbabwe s' land area, mainly in region 1 , will be suitable for growing high yielding late maturing maize varieties. The paper concludes that the currently available maize germplasm in the country is not suitable for the projected climate change conditions.
\end{abstract}

Keywords: Climate change, Rainfed production, Maize varieties, Adaptability, Zimbabwe

\section{Introduction}

Climate change has come to be widely accepted as a phenomenon that will require various mitigation and adaptation measures to reduce its negative impacts on the world economy and the livelihoods of millions of people (IPCC, 2007). However, context specific interventions will be critical because of the differential impacts that climate change will have in various parts of the world. For example, the majority of Sub-Saharan African countries, whose economies are largely dependent on agriculture, will have to find better ways of adapting their mostly rainfed agriculture (FAO, 1995), which is already under strain because of arid and semi-arid conditions. It is estimated that large areas under marginal agricultural production will be abandoned, while at the same time new marginal areas will be created because of reduced precipitation and increased evapotranspiration. Crop yields will be reduced by as much as $50 \%$ while crop revenues are estimated to fall by as much as by $90 \%$ (IPCC, 2007). Smallholder farmers, who form the bulk of the farming population in sub-Saharan Africa, will be worst affected because of a lack of capacity to adapt. This underlines the need for interventions that stabilize agricultural production, which are informed by good science. In this regard General Circulation Models (GCMs) that are now widely available are a useful tool (Swart et al., 2002).

GCM models indicate a decline in mean annual rainfall of $40 \%$ under the A2 scenario in much of southern Africa of which Zimbabwe is a part (IPCC, 2007). The region is also expected to experience a $3.7^{\circ} \mathrm{C}$ temperature 
increase in summer and a $4^{\circ} \mathrm{C}$ increase in winter. Such a scenario will considerably worsen agricultural production in a region that is already affected by a combination of high ambient temperatures, low and erratic precipitation, and increased frequency of droughts. Despite the wide availability of climate change models in Africa, effective decision making at the local level does not seem to exist, mainly because of the continental or regional focus of the models, lack of climate data, as well as material and human resources (Hudson \& Jones, 2002; Jenkins et al., 2002). Local level information is crucial for assessing the extent of the preparedness to adapt to climate change of agriculture-based economies such as Zimbabwe.

Zimbabwe is a semi-arid country. Records show that from 1888 when records began, severe droughts have been recorded during the following seasons: 1911/1914, 1946/47, 1960/61, 1972-73, 1982/83, 1991/92, 2002/03, 2004/05 and 2006/07 (Ndlovu, 2009; Chigodora, 1997; Unganai, 1996). Mid-season droughts are becoming more intense (Ndlovu, 2009). The droughts tend to have a direct impact on the performance of the country's economy (Glantz et al., 2007). For example, the 1982/83 drought resulted in a US\$360 million loss in direct agricultural production and US\$120 million in drought relief costs. The 1991/1992 drought caused the country's Gross Domestic Product (GDP) to fall by eight percent in real terms and agriculture's contribution to GDP by three percent (Chimhou et al., 2010). The combination of low rainfall and production constraints causes millions of people to suffer from chronic malnutrition and general food insecurity. In Zimbabwe food security is generally defined in terms of the availability of maize (Zea mays), which is the staple food crop.

Zimbabwe has 32 million hectares of agricultural land of which 16.4 million hectares is found in communal lands where most of the maize is grown under rainfed conditions (Makadho, 1996). The country is divided into five agro-ecological regions on the basis of the amount of rainfall received (Vincent \& Thomas, 1962), which is mainly determined by latitude and altitude. In general the northern areas of the country experience wetter conditions than the southern areas, and low lying areas are drier than high altitude areas. Most of the 2.5 million tonnes of maize that the country needs each year for human and livestock consumption is grown under rainfed conditions. The amount and distribution of rainfall affects the size of maize yields that are attained. Low maize yields are associated with low rainfall areas and vice versa. There are, however, other factors that affect yield levels. Smallholder farmers, who mostly grow the crop, attain yields as low as $1 \mathrm{t} / \mathrm{ha}$ compared to $5 \mathrm{t} /$ ha in the commercial farming sector due to the inherent low fertility of the soils and negative socio-economic circumstances.

The bulk of the smallholder farmers farm in the low potential areas of agro-ecological region 4 and 5 . As a consequence crop failure is frequent resulting in widespread food shortages. While technologies such as irrigation and in-field water harvesting hold promise for stabilizing and increasing maize production, they are not adequate for a number of reasons. First, the country has limited irrigation potential, it has around 330000 hectares of irrigable land (FAO, 1995). Second, the irrigation development costs estimated at $\$ 10000 / \mathrm{ha}$ are a hindrance (van der Zaag, 2010; Lankford, 2009). Third, in-field water harvesting techniques have been found to produce variable results partly due to varying socio-economic factors (Munamati \& Nyagumbo, 2010).

In Zimbabwe the degree to which rainfed maize production can adapt to climate change at field level is largely unknown. The earliest study on the impacts of climate change on rainfed maize production in Zimbabwe demonstrated that marginal areas will become less suitable for growing maize producing areas because of a drop in precipitation (Makadho, 1996). The study, however, did not investigate how the different commercially-available maize varieties would adapt to climate change. This can provide valuable information to farmers who must make the necessary adaptation measures. Such prospects are high in a country that has an impressive pedigree in maize breeding (Mashingaidze, 1994). Since Makadho's (1996) work information and knowledge about climate change as a science and as practice has increased, raising the prospects for better accurate assessments of climate change impacts. This paper reports on a study whose aim was to assess the adaptability to climate change of commercially available maize varieties in Zimbabwe.

\section{Methodology}

\subsection{Agro-ecological regions and farming systems}

Most of Zimbabwe (located between $25^{\circ} \mathrm{E}, 16^{\circ} \mathrm{S}$ and $34^{\circ} \mathrm{E}, 23^{\circ} \mathrm{S}$ ) has sub-tropical climate (Rukuni \& Eicher, 1994). Zimbabwe has five agro-ecological zones that are characterized by varied rainfall patterns as shown in Fig. 1 and described in Table 1 . The relatively high elevation of the country has a moderating effect on temperature. As a consequence most areas of the country enjoy lower temperatures than would be expected for the county's latitude. Approximately $20 \%$ of Zimbabwe's landscape is over $1200 \mathrm{~m}$ above sea level, while $60 \%$ is between $600 \mathrm{~m}$ and $1200 \mathrm{~m}$. Altitude ranges from $500 \mathrm{~m}$ in the lowveld, which lies mainly in the south, west and north west, to $2400 \mathrm{~m}$ for the highveld (1 $200-1700 \mathrm{~m})$ that stretches from the central northern areas to the 
Eastern Highlands. Frost incidences occur occasionally during winter in isolated locations particularly in the highveld. Agro-ecological regions 4 and 5 are largely semi-arid with signs of desert-like vegetation in the south western areas. The characteristics of each agro-ecological region influences the type of agricultural production that can be undertaken as indicated in Table 1. However, the manipulation of the biophysical environment can alter the agricultural activities that are undertaken. For example irrigation has transformed the semi-arid southeast lowveld into a sugar cane and wheat growing area.

Maize remains the preferred crop in most smallholder areas. The majority of the smallholder farmers who farm in regions 4 and 5 continue to grow the crop even though the climatic conditions are not suitable. This is because maize has superior processing qualities compared to small grains (such as sorghum and millets) that are better climatically suited to the area.

\subsection{Modeling maize varieties to climate change}

\subsubsection{Climate change scenarios}

The adaptability of maize varieties to climate change in Zimbabwe was assessed on the basis of 2010/11, 2020, 2050 and 2080 climate change scenarios (showing annual temperature and precipitation distribution) using the CGCM 3.1-T47 model produced by Canadian Centre for Climate Modeling and Analysis (CCCMA) (CCCMA, 2010). The model uses the A2a scenario, which describes a highly heterogeneous future world (Worldclim, 2011). The main driving forces are a high rate of population growth, increased energy use, land-use changes and slow technological change. The model assumes that things will continue the way they are with little or no shift towards mitigation strategies (CIAT, 2011). On the basis of downscaled climate data the time datasets shown in Table 2 were used for the modeling process.

The datasets were downloaded from website http://gisweb.ciat.cgiar.org/GCMPage. These periods were arrived at using the full present day $(20 \mathrm{C} 3 \mathrm{M})$ monthly time series, with calculated 30 year running means around 1985 (1961-1990) as a baseline for each of the GCMs and 4 variables of interest namely minimum, maximum and mean temperatures and total precipitation.

\subsubsection{Classification of maize varieties}

Brochures of the country's three main seedhouses (Seed-Co, Pannar and Pioneer) were acquired and studied (Table 3). On the basis of number of days to maturity, seedhouses classify the varieties as early maturing (120-140 days), medium maturing (120 - 150 days) and late maturing (135- 150 days). Seed-Co has a fourth group called very early maturing whose growing period is estimated to be between 120 and 132 days. Yield generally increases from very early to late maturing varieties while drought resistance generally increases in the reverse order. For modeling purposes the varieties were categorized as shown in Table 4.

\subsubsection{Assessing adaptability of maize varieties}

Assessing the adaptability of the maize varieties to the different climate change scenarios was undertaken using the cropping model developed by the International Centre for Tropical Agriculture (CIAT), with the support of Bioversity International and the International Potato Centre (CIP) (CIAT, 2010). This is a simple mechanistic model based on the Food and Agriculture Organisation (FAO) database of crop ecological requirements called Ecocrop (CIAT, 2011). The model uses temperature and precipitation thresholds to evaluate the suitability of a certain place to hold a certain crop species. It obtains input climate data from the WorldClim database (Worldclim, 2011). The model also takes into account the elevation of the landscape because of its impact on temperature and precipitation. Using these parameters, the model computes a suitability index for temperature and rainfall separately in order to compute a final suitability rating by multiplying temperature and precipitation suitabilities. The model was executed in the GIS software called DIVA- GIS which is a computer programme for mapping and analyzing spatial data with a particular emphasis on analyzing the distribution of organisms to elucidate geographic and ecological patterns (Hijmans et al., 2005). For the purposes of using the Ecocrop model, the commercial maize varieties available in Zimbabwe were grouped into three groups based on the length of their days to maturity (Table 4). Table 5 shows the parameters that were used to assess the suitability of maize to changes in climate.

For this study the CGCM 3.1-T47 climate model (CCCMA, 2011) was used under the SRES A2a story-line scenario, a scenario that describes a "continue as we are" approach where inadequate mitigation measures are taken (Ramirez \& Jarvis, 2010). Climate data that included maximum temperature (t-max), minimum temperature (t-min) altitude and precipitation (prec) were downloaded from the Worldclim downscaled database at the Worldclim website (http://www.worldclim.org/) for current (2010/2011), 2020, 2050 and 2080 at a 
resolution of $2.5^{\circ} \times 2.5^{\circ}$ (approximately $4.5 \times 4.5 \mathrm{~km}$ ). The climate scenarios were used to produce suitability maps for each of the three groups of maize varieties.

In order to calculate the area that is suitable for growing maize, a shapefile of Zimbabwe and its agro-ecological regions was used to georeference the Ecocrop model. This provided a means for the production of suitability maps for the different maize varieties. Using the parameters in Table 5, the Ecocrop model was used to produce climatic maps for 2011/12 (current), 2020s, 2050s and 2080s for temperature and rainfall, and the suitability maps for the three maize variety groups and 2011/12, 2020s, 2050s and 2080s The Ecocrop model uses monthly average temperatures, monthly average rainfall and elevation data to determine the probability of successfully growing a maize crop in 2.5 arc second squares representing small square areas of approximately $4.5 \mathrm{~km}$ length.

The maps were used to calculate the areas with suitability above $50 \%$ threshold. This assumes at least a $50 \%$ chance of achieving the intended maize harvest by the farmer given the temperature and precipitation conditions from the climate model. A Windows application was created using Microsoft Visual Studio and Microsoft Access to calculate areas with suitabilities above $50 \%$ probability of successfully growing a maize crop.

The parameters shown in Table 5 were used as input into the Ecocrop Model after geo-referencing Zimbabwe. Maps of the variety groups that were suitable for current (2011/12), 2020s, 2050s and 2080s climates were produced.

\section{Results}

\subsection{Extent of agro-ecological regions under different climate change scenarios}

Figure 2 shows base maps of average annual rainfall and average annual temperature distribution for Zimbabwe in the current state (i.e. as of 2010/11 season) as produced with DIVA GIS. The same procedure was used to produce maps for the 2020, 2050 and 2080 average annual rainfall and temperature maps (Figure 3 and 4). Figure 3 and 4 show a shift towards drier conditions in the 2020s. By 2080, most of Zimbabwe's land area will experience annual rainfall of below $610 \mathrm{~mm}$. The Eastern Highlands will experience slightly reduced annual precipitation, and will remain the wettest area in the country with high probability of rainfall above $2000 \mathrm{~mm}$ per year. The average annual temperatures are expected to increase in the southern and north-western portions of the country. By 2080 it is predicted that there will be a general increase in areas with average annual temperatures above $25^{\circ} \mathrm{C}$. The Eastern Highlands will remain the coolest areas due to high elevation. The southern and western regions will become drier. Drier conditions will extend from the south-western regions into the middle veld. This will be accompanied by higher average annual temperatures.

Figure 5 shows the change in area covered by each of the agro-ecological rainfall conditions between current and future conditions while Figure 6 shows the magnitude change in area. Regions 4 and 5 show an increase in area covered. This means that more of Zimbabwe's land area will increasingly become drier as shown in Figure 6 . Regions 2 and 3 will decrease in area owing to increased drying. Interestingly, region 2 shows a slight rise in area in the 2020. This suggests an increase in rainfall to between $800 \mathrm{~mm}$ and $1000 \mathrm{~mm}$ for some areas which currently are not in this rainfall range. The highland areas of region 1 will maintain a constant area below $4 \%$ with a marginal decline. Overall, these changes suggest a shift in conditions toward more a semi-arid climate. Much of the country will become less suitable for growing maize. As most smallholder farmers farm in regions 3, 4 and 5 , it implies that more farmers will be unable to rely on rainfed maize production. As will be discussed in section 4.2 it will become more difficult to grow even those varieties that are classified as drought resistant.

\subsection{Suitability of different varieties}

Figure 7 shows the downward trend in the area under maize production for different maize varieties. Figures 8-10 show the trend for the different agro-ecological regions. Table 6 shows a decrease in the gross area suitable for maize production across all the maize varieties. Figure 8 shows that the area suitable for growing early maturing varieties will not change. There, is however, progressive decline in regions 3,4 and 5 . Region 5 will be the most affected with potential suitable area falling to below $1 \%$ around 2080 .

For medium maturing maize varieties, only region 1 maintains maximum suitability while regions $2,3,4$ and 5 all show steadily decline. The trend also shows that apart from region 3 , the area suitable for medium maturing maize production will fall below $20 \%$ in regions 4 and 5 . The changes can be related to the change in rainfall patters as shown in Figure 5. For late maturing maize varieties, even region 1 shows a steady decline in the maize growing suitable area. The area under regions 2, 3, 4 and 5 show a sharp decline between 2010 and 2020, and a steady decline to below $10 \%$ by 2080 . This means that short season varieties have a better chance of coping with the changes in climate when compared to medium and late maturing varieties. Region 5 will be most affected with virtually little or no conditions suitable for maize production owing to the increase in temperature 
and reduction in precipitation. In Zimbabwe as a whole, late maturing varieties will perform badly with an expected decrease of $42.94 \%$ between current conditions and 2020. Late maturing varieties will increasingly be more difficult to grow to an extent that only $2 \%$ of Zimbabwe will be suitable for growing it by the 2080s. Medium maturing varieties will also suffer large suitability reductions. The early maturing varieties will remain the most viable with $23 \%$ of Zimbabwe suitable for growing this category of varieties. In general, the greatest reduction in suitability will occur between current conditions and conditions expected in the 2020s. In other words the most drastic effects on maize production in Zimbabwe are expected within the next two decades. Figure 11, 12 and 13 show maps of the distribution of suitabilities for the different agro- ecological zones. The maps show much of the south and southwester areas of Zimbabwe are highly unsuitable for growing anything for all three variety groups. Figures 11 and 12 show that with medium and late maturing maize varieties, much of Zimbabwe will be unable to support rainfed maize production. By 2080 no place will be suitable place for growing late maturing varieties except in the mountainous Eastern Highlands.

\section{Discussion and Conclusions}

The data that has been presented in this paper supports the general view that African agriculture is vulnerable to climate change (Adjei-Nsiah et al., 2001; Dinar et al., 2008; Dixon et al., 2003), and that the vulnerability is exacerbated by widespread poverty, mismanagement of natural resources and inequitable access to productive resources such as land, and (Dixon et al, 2003). A number of studies have attempted to shed light on understanding the drivers and impacts of climate change (IPCC, 2007; Smit \& Wandel, 2006; Smit \& Skinner, 2002; Swart et al., 2002) as well as adaptation strategies. Of interest to this paper are studies that seem to suggest that local communities are aware of the phenomenon of climate change and are devising strategies to address the problem as reported in Ghana (Adjei-Nsiah et al., 2010) and Tanzania (Mary \& Majule, 2009). Dixon et al. (2003), however seem less convinced that such a capacity exists because of underdeveloped human and institutional capacity as well as absence of adequate infrastructure.

In more specific terms there is a belief that crop diversification, growing drought tolerant crops and crop varieties and undertaking water harvesting will do the trick (Adjei-Nsiah et al., 2010; Mary \& Majule, 2009; Kamukondiwa, 1996). The empirical material presented in this paper shows that these adaptation measures are likely to be compromised by a lack of suitable germplasm for the projected climatic conditions. For example, in Zimbabwe the prime areas for growing maize (regions 1 and 2) are projected to decrease by $14 \%$, while the low potential areas of regions 4 and 5 will increase by $40 \%$. This is worsened by the fact that the prime areas of regions 1 and 2 will largely be suitable for growing low yielding early and medium maturing maize varieties. The other regions will be not be suitable for growing medium and late maturing varieties. Across the entire country it will not be feasible to grow late maturing varieties except in region 1 . Unfortunately region 1 accounts for only less than $2 \%$ of the country's land area. Moreover its topography is not suitable for field crops such as maize. Only the early maturing varieties will perform better.

The fact that low yielding varieties will mostly be suitable means that food insecurity will increase. For the majority of smallholder farmers in regions 4 and 5, who grow maize under marginal conditions, they will not be able to harvest anything. Thus the capacity of farmers will be eroded because of the limited germplasm. If maize production is to be successfully grown in Zimbabwe under the projected climate change conditions the germplasm that is available to farmers needs to be widened. Against this background it can be concluded that the claims of local adaptation capacity may be exaggerated.

\section{References}

Adjei-Nsiah, S., Issaka, R.N., Fening, J.O., Mapfumo, P., Anchirina, V., \& Giller, K.E. (2010.) Farmers; Perceptions of Climate Change and Variability and Existing Opportunities for Adaptation in Wenchi Area of Ghana. The International Journal of Climate Change: Impacts and Responses, 2(2), 49-60.

Canadian Centre for Climate Modeling and Analysis. (2010). The Fourth Generation Coupled Global Climate Model. [Online] Available: http://www.ec.gc.ca/ccmac-cccma/Default.asp?lang=En\&n=4596B3A2-1

Chigodora, J. (1997). Famine and Drought: The Question of Food Security in Zimbabwe, India Musokotwane Environment Resource Centre for Southern Africa (IMERCSA), Zimbabwe.

Chikizho, C. (2010). Applied Social Research and Action Priorities for Adaptation to Climate Change and Rainfall Variability in the Rainfed Agricultural Sector of Zimbabwe. Physics and Chemistry of the Earth, 35, 780-790. http://dx.doi.org/10.1016/j.pce.2010.07.006

Chimhou, A., Manjenga, M., \& Feresu, S. (2010). Moving Forward in Zimbabwe: Reducing Poverty and promoting Growth, Second Edition, Institute of Environmental Studies, University of Zimbabwe, Zimbabwe. 
CIAT (International Centre for Tropical Agriculture). (2011). Downscaling: Statistical Downscaling (Delta Method). [Online] Available: http://www.ccafs-climate.org/download_sres.html

Dinar, A., Hassan, R., Mendelsohn, R., \& Benhin, J. (2008). Climate Change and Agriculture in Africa: Impact Assessment and Adaptation strategies, Centre for Environmental and Policy in Africa, London: Earthscan.

Dixon, R.K., Smith, J., \& Guill, S. (2003). Mitigation and Adaptation Strategies for Global Change, 8, 93-113. http://dx.doi.org/10.1023/A:1026001626076

FAO (Food and Agriculture Organisation). (1995). Irrigation in Africa in figures. Paper 7. Rome, Italy.

Glantz, M. H., Betsille, M., \& Crandall, K. (2007). Food Security in Southern Africa: Assessing the Use and Value of ENSO Information, Environmental and Societal Impacts Group (ESIG), National Center for Atmospheric Research (NCAR), Boulder, CO 80307 USA

Hijmans, R. J., Cameron, S. E., Parra, J. L, Jones, P. G., \& Jarvis, A. (2005). Very high resolution interpolated climate surfaces for global land areas. International Journal of Climatology, 25, 1965-1978. http://dx.doi.org/10.1002/joc.1276

Hudson, D.A., \& Jones, R.G. (2002). Regional climate model simulations of present day and future climates of SouthernAfrica. Technical Note 39, Hadley Centre, Bracknell.

Intergovernmental Panel on Climate Change. (2007). Africa. Climate Change 2007: Impacts, Adaptation and Vulnerability. Contribution of Working Group II to the Fourth Assessment Report of the Intergovernmental Panel on Climate Change, M.L. Parry, O.F. Canziani, J.P. Palutikof, P.J. van der Linden and C.E. Hanson, Eds., Cambridge University Press, Cambridge. 433-467.

Jenkins, G.S., Adamou, G., \& Fongang, S. (2002). The challenges of modeling climate variability and change in West Africa. Climatic Change, 52, 263-286. http://dx.doi.org/10.1023/A:1013741803144

Kamukondiwa W. (1996). Alternative food crops to adapt to potential climatic change in southern Africa. Climate Research, 6, 153-155. Scientific and Industrial Research and Development Centre (SIRDC), Environment and Remote Sensing Institute, Harare, Zimbabwe. http://dx.doi.org/10.3354/cr006153

Lane1, A., \& Jarvis, A. (2007). Changes in Climate will modify the Geography of Crop Suitability: Agricultural Biodiversity can help with Adaptation, Bioversity International, Via dei Tre Denari 472/a, 00057 Maccarese, Rome, Italy.

Lankford, B. (2009). Viewpoint -The Right Irrigation? Policy Directions for agricultural water management in sub-Saharan Africa. Water Alternatives, 2(3), 476-480.

Makadho J. M. (1996). Potential effects of climate change on corn production in Zimbabwe, Climate Research, 6, 147-151. http://dx.doi.org/10.3354/cr006147

Mary, A.L., \& Majule, A.E. (2009). Impacts of Climate Change, Variability and Adaptation Strategies on Agriculture in Semi Arid Areas of Tanzania: The Case of Manyoni District in Singida Region, Tanzania, African Journal of Environmental Science and Technology, 3(8), 206-218. [Online] Available: http:/www.academicjournal.org/AJEST

Mashingaidze, K. (1994). Maize Research and Development. In: Rukuni, M. and Eicher, C.K. (eds.) Zimbabwe is Agricultural Revolution, Harare, University of Zimbabwe Publications. 208-218.

Mubaya, C. P., Njuki, J., Liwenga, E., Mutsvangwa, E. P., \& Mugabe, F. T. (2010). Perceived impacts of climate related parameters on smallholder farmers in Zambia and Zimbabwe, Journal of Sustainable Development in Africa, 12(5). [Online] Available: http://www.jsd-africa.com/Jsda/V12No5_Fall2010_A/PDF/Perceived\%20Impacts\%20of\%20Climate\%20RElate d\%20Parameters\%20(Mubaya,\%20Njuki,\%20Liwenga,\%20Mutsvangwa,\%20Mugabe).pdf

Munamati, M., \& Nyagumbo, I. (2010). In Situ Rainwater Harvesting using Dead Level Contours in Semi-arid Southern Zimbabwe: Insights on the Role of Socio-economic Factors on Performance and Effectiveness in Gwanda District, Physics and Chemistry of the Earth, 35, 699-705. http://dx.doi:10.1016/j.pce.2010.07.029.

Ndlovu, S. (2009). Coping with drought: Research findings from Bulilima and Mangwe Districts, Matabeleland South, Zimbabwe, Zimbabwe Meteorological Services, Harare, Zimbabwe.

Ramirez, J., \& Jarvis, A., (2010). Disaggregation of Global Circulation Model Outputs: Decision and Policy Analysis Working Paper No. 2, International Center for Tropical Agriculture, CIAT, Cali, Colombia, CGIAR Challenge Program on Climate Change, Agriculture and Food Security (CCAFS). 
Rukuni, M., \& Eicher, C. K. (1994). Zimbabwe's Agricultural Revolution. University of Zimbabwe Publications, Mambo Press, Gweru.

Smit, B., \& Skinner, M. (2002). Adaptation options in agriculture to climate change: a typology. Mitigation and Adaptation Practices and Policies for Global Change Volume: 7, Issue: UNFCCC 1992, Publisher: Springer, Pages: 85-114. http://dx.doi.org/10.1023/A:1015862228270

Smit, B., \& Wandel, J., (2006). Adaptation, adaptive capacity and Vulnerability. Global Environmental Change, 16(3), 282-292. http://dx.doi.org/10.1016/j.gloenvcha.2006.03.008

Swart, R., Mitchell, J., Morita, T., \& Raper, S. (2002) Stabilisation scenarios for climate impacts assessment. Global Environ. Chang, 12, 155-165. http://dx.doi.org/10.1016/S0959-3780(02)00039-0

Unganai, L. S. (1996). Historic and future climatic change in Zimbabwe, Climate Research, 6, 137-145, Drought Monitoring Centre, PO Box BE150. Belvedere, Harare, Zimbabwe

United Nations Development Programme, Office to Combat Desertification (UNDP/UNSO) World Meteorological Organization (WMO), (2000). Coping with Drought in Sub-Saharan Africa: Better Use of Climate Information, AGM-1 WMO/TD No. 1035.

Van der Zaag, P. (2010). Viewpoint -Water variability, soil nutrient heterogeneity and market volatility -Wht sub-Saharan Africa's Green Revolution will be location-specific and knowledge-intensitive, Water Alternatives, 3(1), 154-160.

Vincent, V., \& Thomas, R.G. (1962). An agricultural survey of Southern Rhodesia: Part I. Agro-ecological survey, Harare: Government Printer.

WorldClim. (2011). Future climate data download. [Online] Available: http://www.worldclim.org/futdown.htm

Table 1. Characteristics of Zimbabwe's agro-ecological regions

\begin{tabular}{|c|c|c|c|}
\hline $\begin{array}{c}\text { Natural } \\
\text { region }\end{array}$ & Area (ha) & Rainfall $\left(\mathrm{mm} \mathrm{yr}^{-1}\right)$ & Recommended farming system \\
\hline 1 & $\begin{array}{c}613233 \\
(1.56 \%)\end{array}$ & $\begin{array}{c}\text { Rainfall in excess of } 1000 \mathrm{~mm} \text { precipitation in } \\
\text { all months of the year, relatively low } \\
\text { temperatures. }\end{array}$ & $\begin{array}{c}\text { Specialised and diversified farming. } \\
\text { Forestry, fruit, intensive livestock, tea, } \\
\text { coffee }\end{array}$ \\
\hline 2 & $\begin{array}{c}7343059 \\
(18.68 \%)\end{array}$ & $\begin{array}{c}\text { Rainfall between } 750 \mathrm{~mm}-1000 \mathrm{~mm} \text { per year } \\
\text { mainly in summer. }\end{array}$ & $\begin{array}{c}\text { Intensive farming. Crops and intensive } \\
\text { livestock production. }\end{array}$ \\
\hline 3 & $\begin{array}{c}6859958 \\
(17.43 \%)\end{array}$ & $\begin{array}{c}\text { Rainfall between } 650-800 \text {, infrequent but } \\
\text { heavy falls of rainfall, seasonal droughts, } \\
\text { relatively high temperatures. }\end{array}$ & $\begin{array}{c}\text { Semi-intensive farming. Livestock, } \\
\text { fodder and staple and cash crops } \\
\text { like maize, tobacco, cotton. }\end{array}$ \\
\hline 4 & $\begin{array}{c}13010036 \\
(33.03 \%)\end{array}$ & $\begin{array}{c}\text { Rainfall between 450-650mm per year, } \\
\text { frequent seasonal droughts, relatively high } \\
\text { temperatures. }\end{array}$ & $\begin{array}{c}\text { Semi-extensive farming. Livestock } \\
\text { farming, drought tolerant crops. }\end{array}$ \\
\hline 5 & $\begin{array}{c}10288036 \\
(26.2 \%)\end{array}$ & $\begin{array}{c}\text { Rainfall less than 450mm, erratic. Northern } \\
\text { Lowveld may have higher rainfall but } \\
\text { topography and poor soils make it unsuitable } \\
\text { for arable agriculture. }\end{array}$ & $\begin{array}{c}\text { Extensive farming. Extensive cattle } \\
\text { ranching, wildlife farming, crops only } \\
\text { possible with irrigation. }\end{array}$ \\
\hline
\end{tabular}

Source: Adapted from Vincent and Thomas (1962)

Table 2. Time datasets used for future climate conditions

\begin{tabular}{|c|c|}
\hline Time dataset & Remarks \\
\hline $1961-1990$ & Baseline climate, referred to as the current climate used to indicate prevailing climate as of \\
& 2011 or 2010's for this study \\
\hline $2010-2039$ & Referred to as 2020s \\
\hline $2040-2069$ & Referred to as 2050s \\
\hline $2070-2099$ & Referred to as 2080s \\
\hline
\end{tabular}

Source: Ramirez and Jarvis (2010) 
Table 3. Characteristics of commercially available maize varieties in Zimbabwe

\begin{tabular}{|c|c|c|c|c|c|}
\hline Seedhouse & Category & Name of variety & Colour & Days to maturity & Yield potential \\
\hline \multirow{22}{*}{ Seed-Co } & Very Early & SC403 & White & 131 & $1-5$ \\
\hline & Very Early & SC409 & White & 132 & $1-5$ \\
\hline & Very Early & SC411 & White & 132 & $4-8$ \\
\hline & Early & SC506 & Yellow & 132 & $1-6$ \\
\hline & Early & SC513 & White & 137 & $4-8$ \\
\hline & Early & SC517 & White & 134 & $3-6$ \\
\hline & Early & SC525 & White & 134 & $5-10$ \\
\hline & Medium & SC602 & Yellow & 148 & $5-13$ \\
\hline & Medium & SC608 & Yellow & 148 & $5-14$ \\
\hline & Medium & SC621 & White & 148 & $3-8$ \\
\hline & Medium & SC627 & White & 144 & $5-10$ \\
\hline & Medium & SC633 & White & 140 & $6-12$ \\
\hline & Medium & SC635 & White & 142 & $5-10$ \\
\hline & Medium & SC637 & White & 148 & $6-13$ \\
\hline & Late & SC710 & White & 152 & $7-13$ \\
\hline & Late & SC709 & White & 151 & $8-13$ \\
\hline & Late & SC713 & White & 151 & $8-11$ \\
\hline & Late & SC715 & White & 152 & $6-11$ \\
\hline & Late & SC717 & White & 156 & $6-10$ \\
\hline & Late & SC719 & White & 158 & $7-13$ \\
\hline & Late & SC721 & White & 150 & $6-13$ \\
\hline & Late & SR52 & White & 151 & $7-13$ \\
\hline \multirow{8}{*}{ Pannar } & Late & ZS206 & Yellow & 150 & $5-13$ \\
\hline & Early & PAN4M-19 & White & NA & NA \\
\hline & Early & PAN413 & White & $125-135$ & NA \\
\hline & Medium & PAN53 & White & $130-140$ & NA \\
\hline & Medium & PAN67 & White & $130-140$ & NA \\
\hline & Medium & PAN6243 & White & $135-145$ & NA \\
\hline & Late & PAN6777 & White & $135-150$ & 11 \\
\hline & Medium & PAN14 & Yellow & $135-145$ & NA \\
\hline \multirow{6}{*}{ Pioneer } & Medium & PHB30G19 & White & $130-145$ & 12 \\
\hline & Medium & PHB30B50 & Yellow & $130-145$ & 11 \\
\hline & Early & PHB3253 & White & $120-140$ & 9 \\
\hline & Early & PHB30G97 & White & $120-140$ & 9 \\
\hline & Medium & PHB30D79 & White & $130-145$ & 10 \\
\hline & Very early & $\mathrm{P} 2859 \mathrm{~W}$ & White & $115-128$ & 9 \\
\hline
\end{tabular}

Source: Pannar, Seed-Co and Pioneer product brochures

Table 4. Classification of maize varieties according to days to maturity for modeling purposes

\begin{tabular}{|c|c|c|}
\hline Variety & Minimum & Maximum \\
\hline Late & 145 & 160 \\
\hline Medium & 135 & 145 \\
\hline Early & 115 & 135 \\
\hline
\end{tabular}


Table 5. Parameters used in the Ecocrop model to assess suitability of maize to climate change

\begin{tabular}{|c|c|c|c|}
\hline Variety & Late & Medium & Early \\
\hline G-Min (days) & 145 & 135 & 115 \\
\hline G-Max (days) & 160 & 145 & 135 \\
\hline G-Used (days) & 150 & 140 & 130 \\
\hline Kill-Temp $\left({ }^{\circ} \mathrm{C}\right)$ & 0 & 0 & 0 \\
\hline T-Min $\left({ }^{\circ} \mathrm{C}\right)$ & 10 & 10 & 10 \\
\hline T-Opt-Min $\left({ }^{\circ} \mathrm{C}\right)$ & 18 & 18 & 18 \\
\hline T-Opt-Max $\left({ }^{\circ} \mathrm{C}\right)$ & 33 & 33 & 33 \\
\hline T-Max $\left({ }^{\circ} \mathrm{C}\right)$ & 47 & 47 & 47 \\
\hline R-Min $(\mathrm{mm})$ & 800 & 650 & 500 \\
\hline R-Opt-Min $(\mathrm{mm})$ & 1000 & 800 & 650 \\
\hline R-Opt-Max $(\mathrm{mm})$ & 1200 & 1200 & 1200 \\
\hline R-Max $(\mathrm{mm})$ & 1800 & 1800 & 1800 \\
\hline
\end{tabular}

Notes: G-min, G-max and G-used represent the minimum, maximum and generally used days to maturity 2 . Kill-temp, T-min, T-opt-min and T-opt-max represent the kill temperature, optimum minimum temperature, optimum maximum temperature and maximum temperature respectively. 3. R-min, R-opt-min, R-opt-max and $\mathrm{R}$-max represent the minimum, optimum minimum, optimum maximum and maximum water required over the growing season to reach physiological maturity.

Table 6. Estimated area covered by different maize varieties for 2010-2080 period at 50\% suitability threshold

\begin{tabular}{|c|c|c|}
\hline Scenario period & Maize Variety & Area covered(x 100 ha) \\
\hline \multirow{3}{*}{2010} & Early & 373734 \\
\cline { 2 - 3 } & Medium & 291721.5 \\
\cline { 2 - 3 } & Late & 188325 \\
\hline \multirow{3}{*}{2020} & Early & 235284.75 \\
\cline { 2 - 3 } & Medium & 139988.25 \\
\cline { 2 - 3 } & Late & 20938.5 \\
\hline \multirow{3}{*}{2050} & Early & 158274 \\
\cline { 2 - 3 } & Medium & 37462.5 \\
\cline { 2 - 3 } & Late & 11481.75 \\
\hline \multirow{2}{*}{2080} & Early & 88310.25 \\
\cline { 2 - 3 } & Medium & 16503.75 \\
\cline { 2 - 3 } & Late & 7593.75 \\
\hline
\end{tabular}




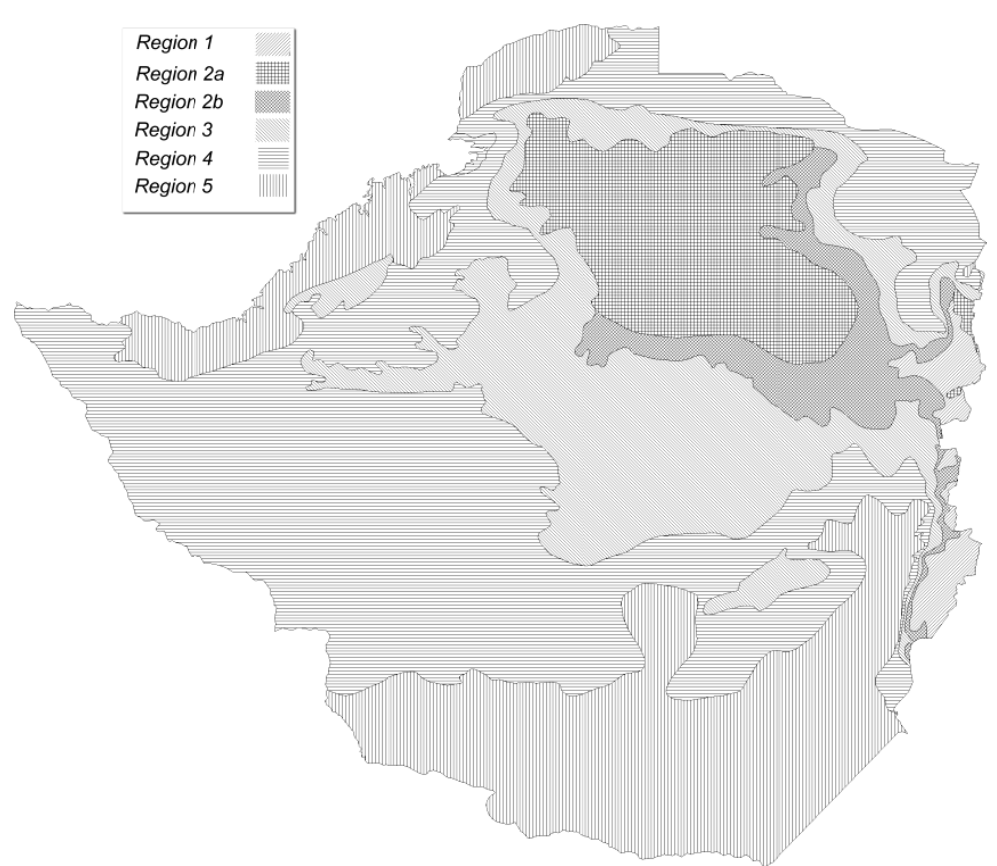

Figure 1. Agro-ecological regions of Zimbabwe (Source: University of Zimbabwe Department of Geography, 2011)

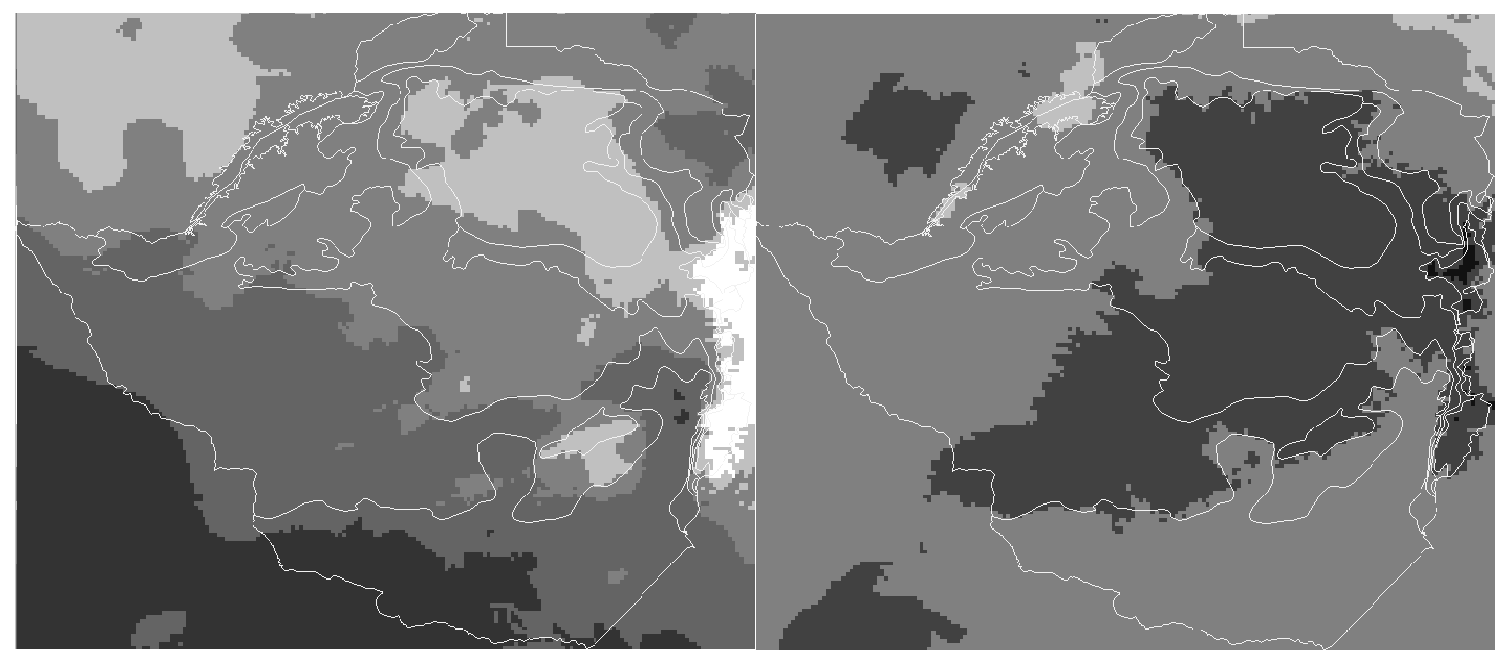

Figure 2. Zimbabwe average annual precipitation $(\mathrm{mm})$ and average annual temperature $\left({ }^{\circ} \mathrm{C}\right)$ base maps for $2010 / 11$

Note: For precipitation the white indicates show higher average annual precipitation and the darker areas show lower precipitation corresponding to 5 ranges namely $>1000 \mathrm{~mm}, 800-1000 \mathrm{~mm}, 650-1000 \mathrm{~mm}, 450-650 \mathrm{~mm}$ and $<450 \mathrm{~mm}$. For temperature the white indicates show higher average annual temperatures and the darker areas show lower average temperatures corresponding to 5 ranges namely $30-35{ }^{\circ} \mathrm{C}, 25-30{ }^{\circ} \mathrm{C}, 20-25^{\circ} \mathrm{C}$ and $15-20{ }^{\circ} \mathrm{C}$ and $10-15^{\circ} \mathrm{C}$. 


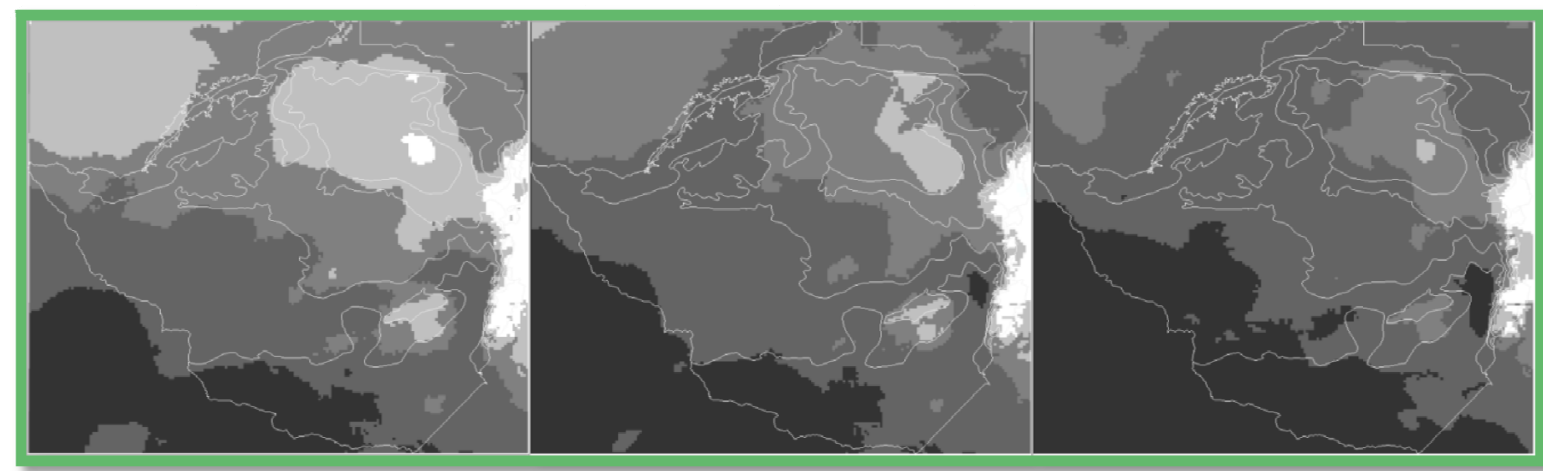

Figure 3. Zimbabwe maps of precipitation distribution changes for 2020, 2050 and 2080

Note: For precipitation the white indicates show higher average annual precipitation and the darker areas show lower precipitation corresponding to 5 ranges namely $>1000 \mathrm{~mm}, 800-1000 \mathrm{~mm}, 650-1000 \mathrm{~mm}, 450-650 \mathrm{~mm}$ and $<450 \mathrm{~mm}$.

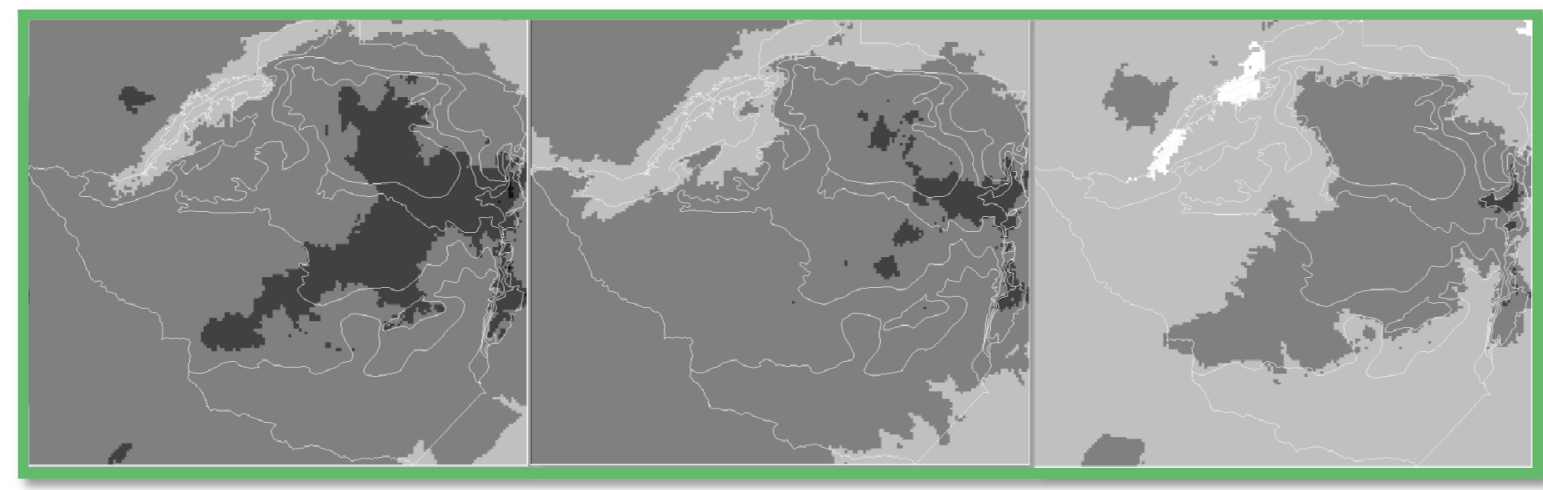

Figure 4. Zimbabwe maps of temperature distribution changes for 2020, 2050 and 2080

Note: The temperature map shows dark areas representing the highest average annual temperatures and the light areas representing lower temperatures corresponding to ranges $30-35^{\circ} \mathrm{C}, 25-30^{\circ} \mathrm{C}, 20-25^{\circ} \mathrm{C}, 15-20{ }^{\circ} \mathrm{C}$ and $10-15$ ${ }^{\circ} \mathrm{C}$.

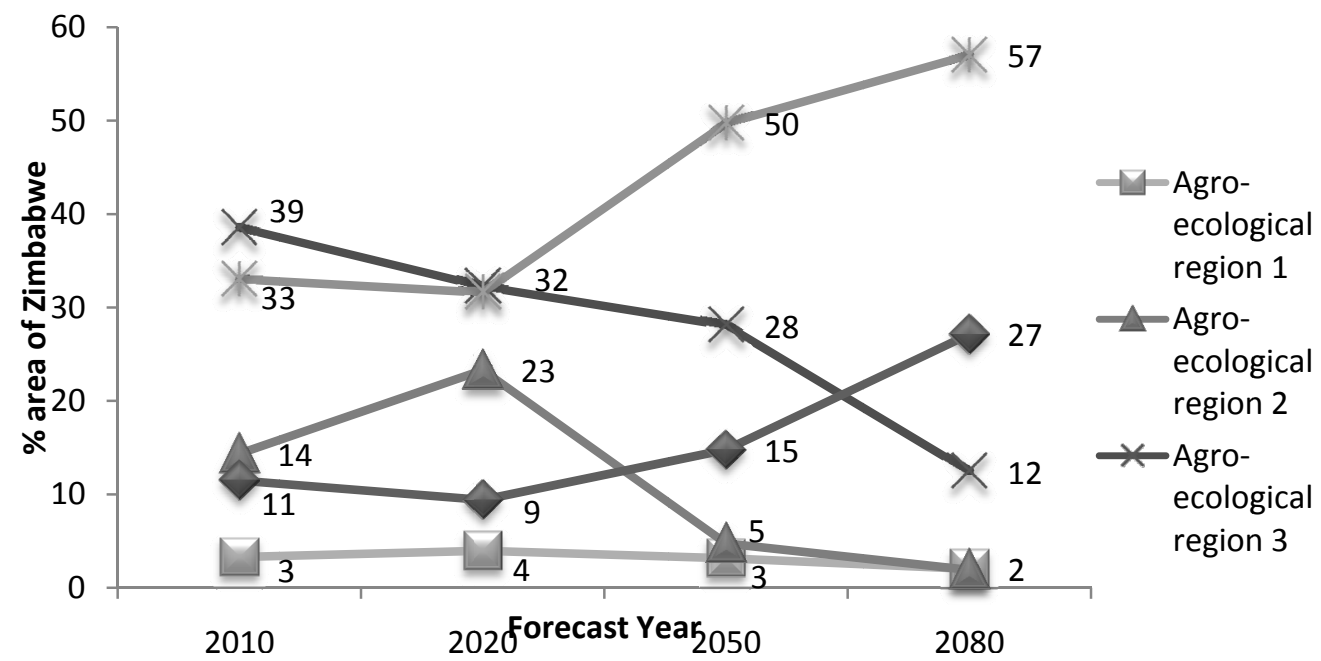

Figure 5. Changes in \% aggregate area covered by each agro-ecological region in Zimbabwe between 2010 and 2080 


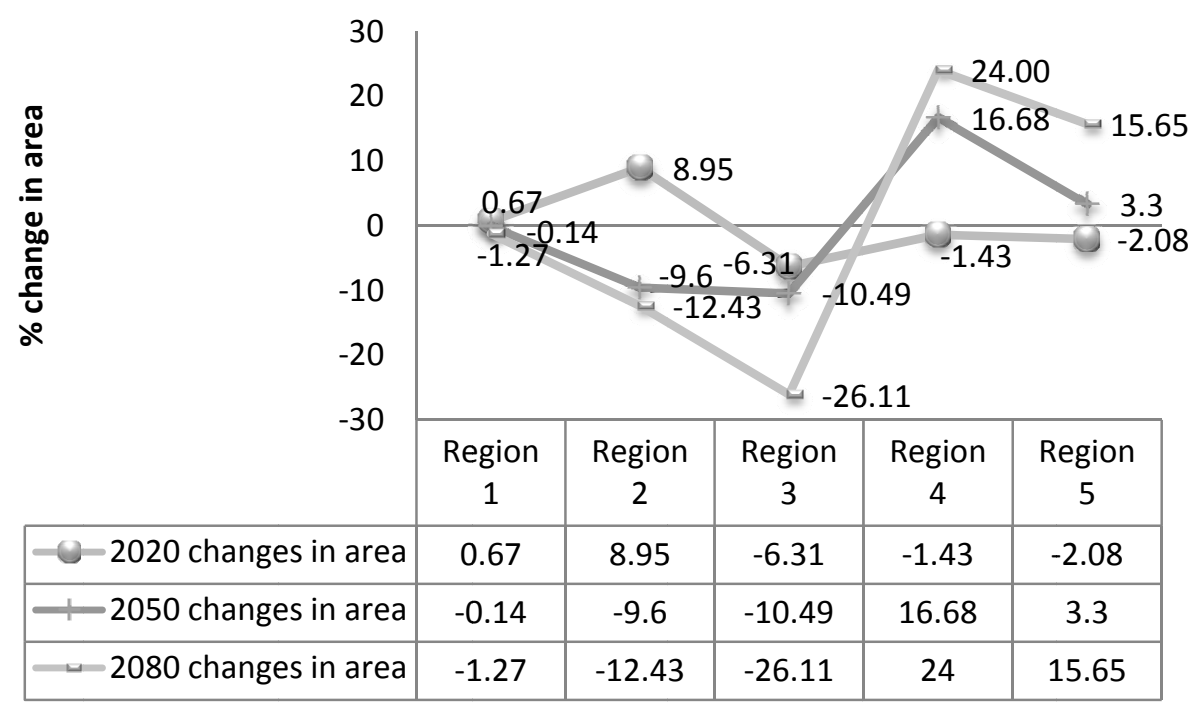

Figure 6. Percent change in aggregate area covered by each agro-ecological region in Zimbabwe for 2020. 2050 and 2080 seasons (all use 2010 is the base year)

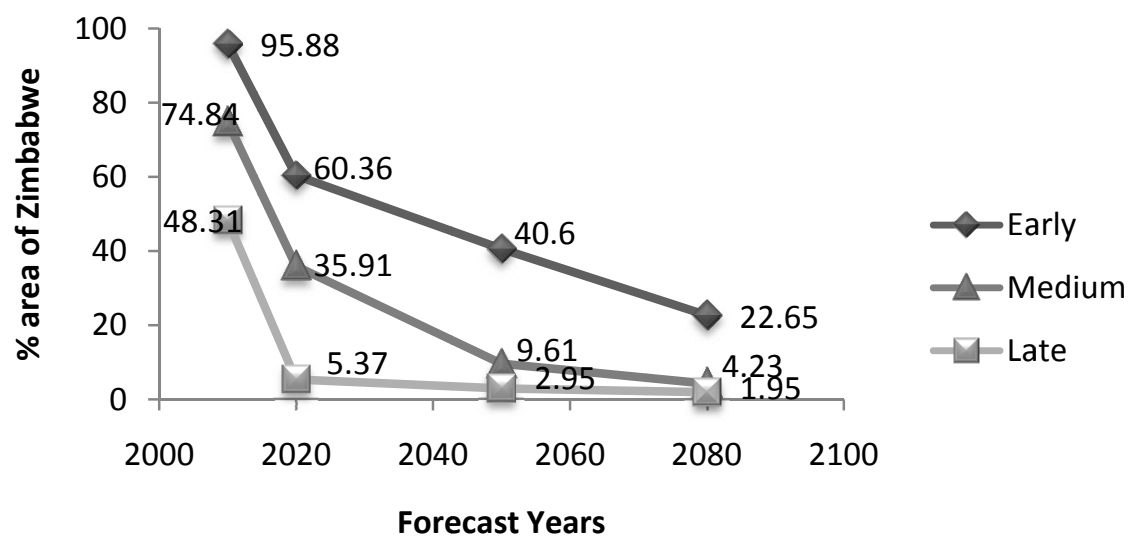

Figure 7. Area of Zimbabwe suitable for early, medium and late maturing varieties at $50 \%$ and above suitability threshold

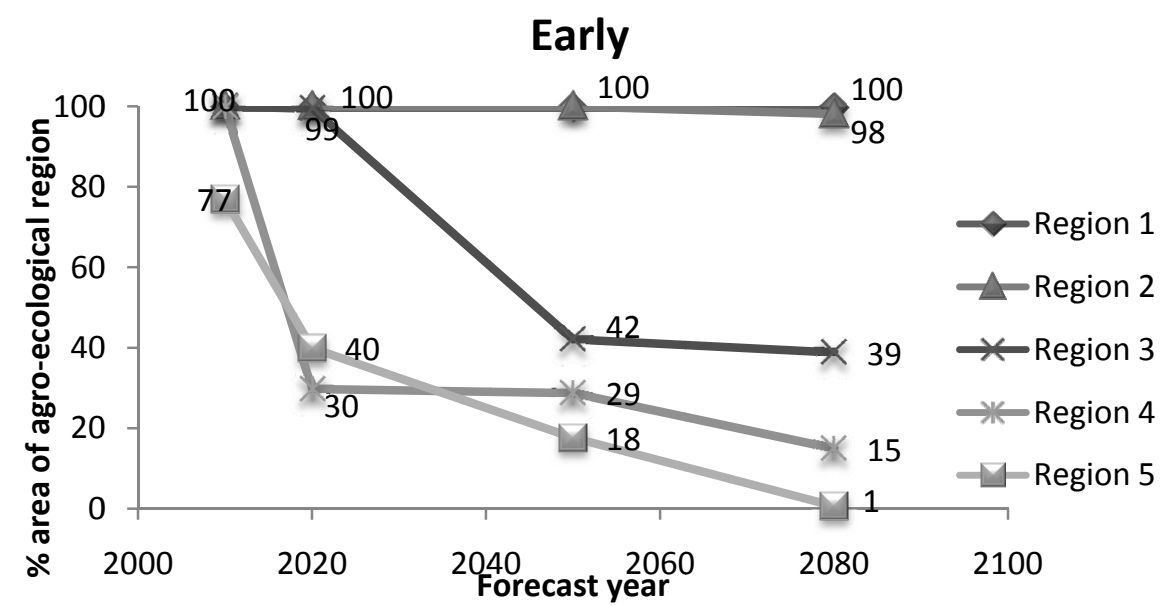

Figure 8 . Change in suitability of early maturing varieties in each agro-ecological region for $50 \%$ suitability threshold 


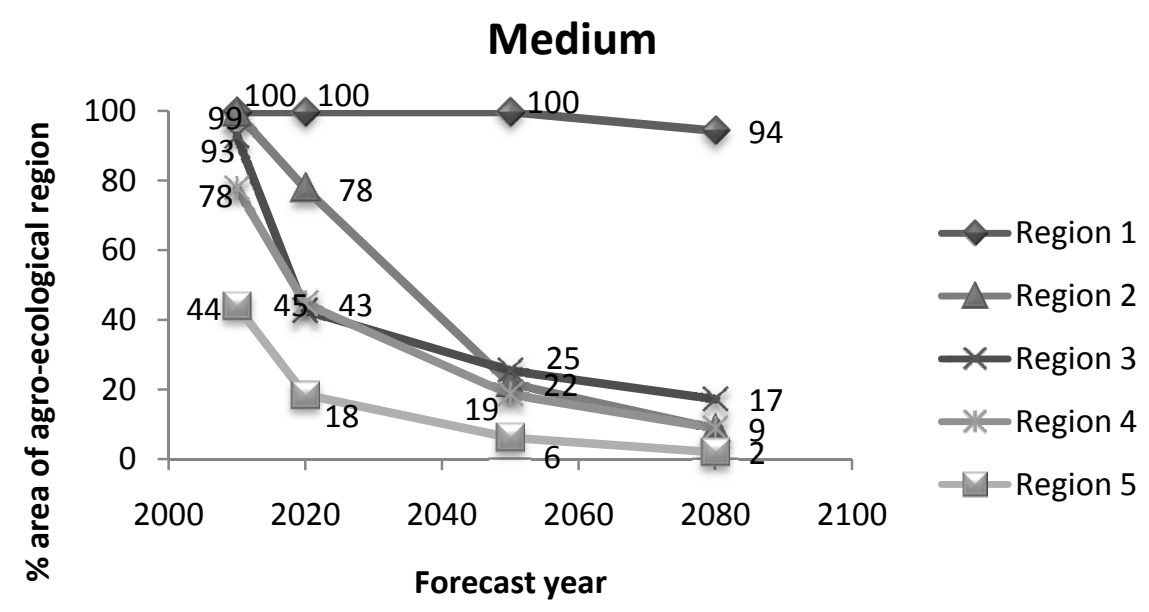

Figure 9. Change in suitability of medium maturing varieties in each agro-ecological region for $50 \%$ suitability threshold

\section{Late}

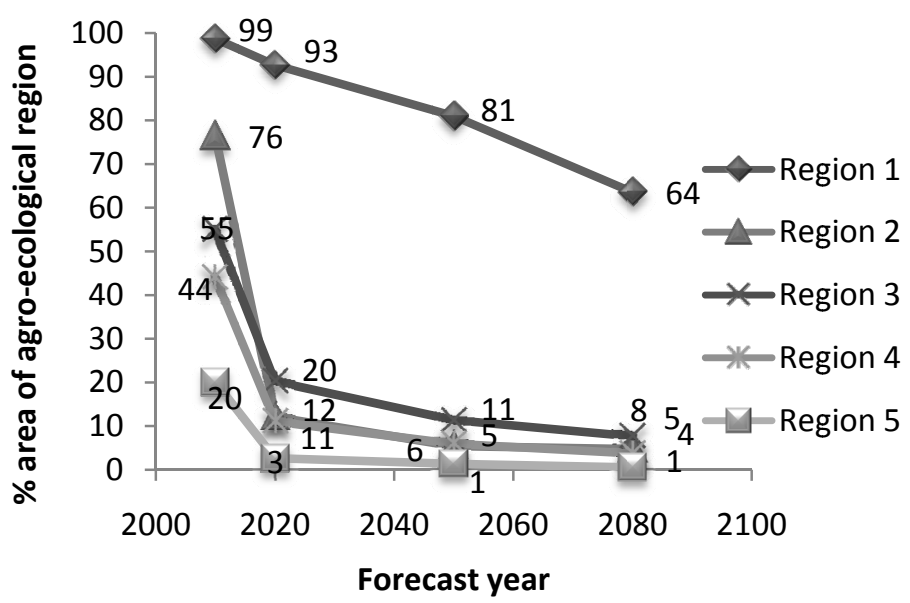

Figure 10. Change in suitability of late maturing varieties in each agro-ecological region for $50 \%$ suitability threshold 


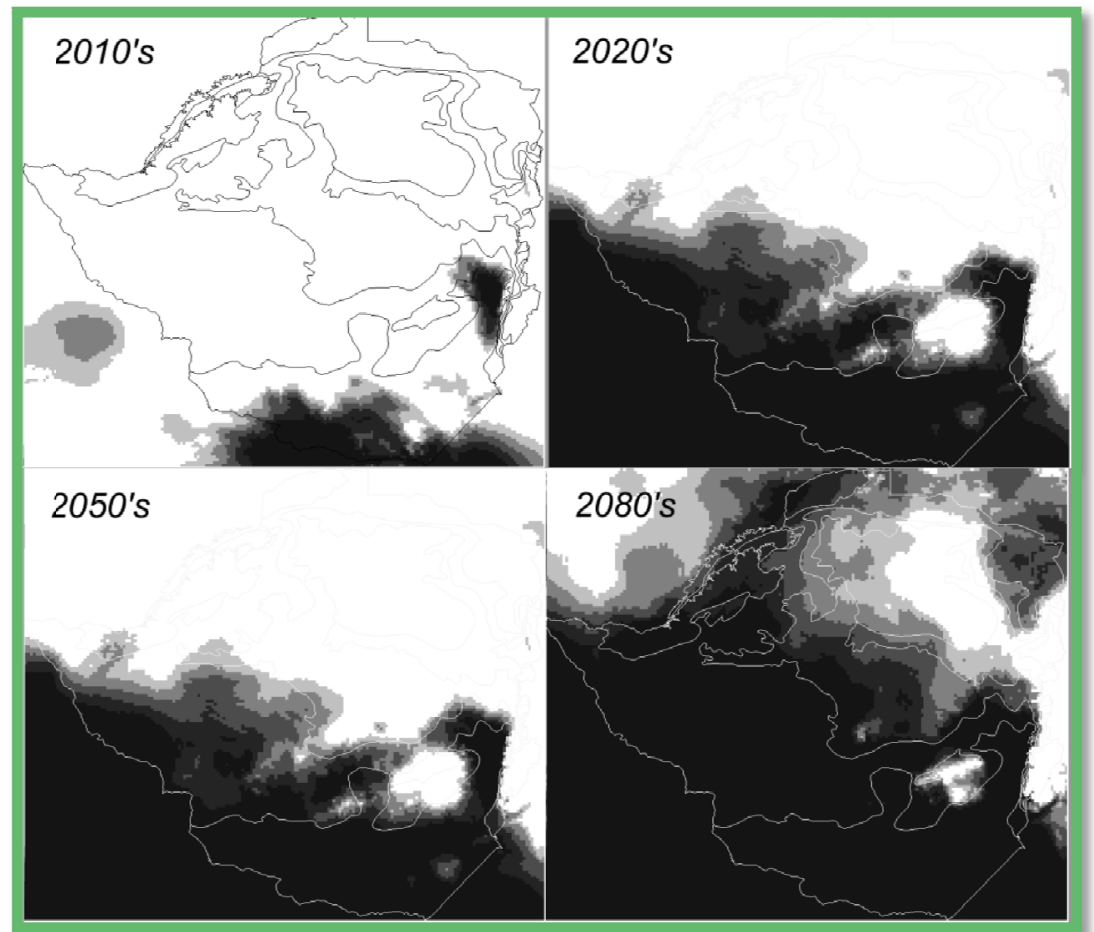

Figure 11. Map showing change in suitability of early maturing maize from current to 2080's

White indicates excellent suitability (80-100\%), light Grey represents Very suitable areas (60-80\%), medium Grey represents suitable areas (40-60\%), Grey represents marginal suitability (20-40\%) while dark grey indicates areas with very marginal suitability between 0 and $20 \%$.

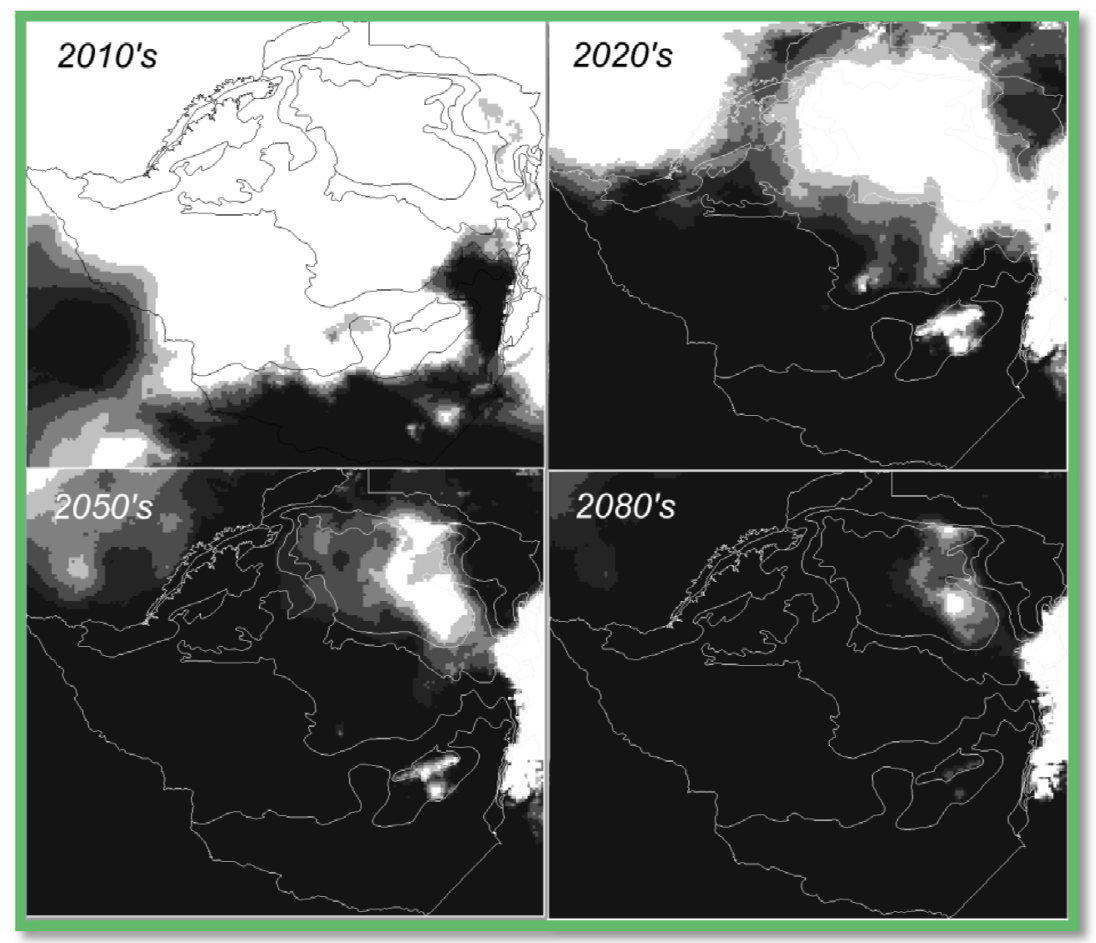

Figure 12. Map showing change in suitability of medium maturing maize from current to 2080's

White indicates excellent suitability (80-100\%), light Grey represents Very suitable areas (60- 80\%), medium Grey represents suitable areas (40-60\%), Grey represents marginal suitability (20-40\%) while dark grey indicates areas with very marginal suitability between 0 and $20 \%$. 


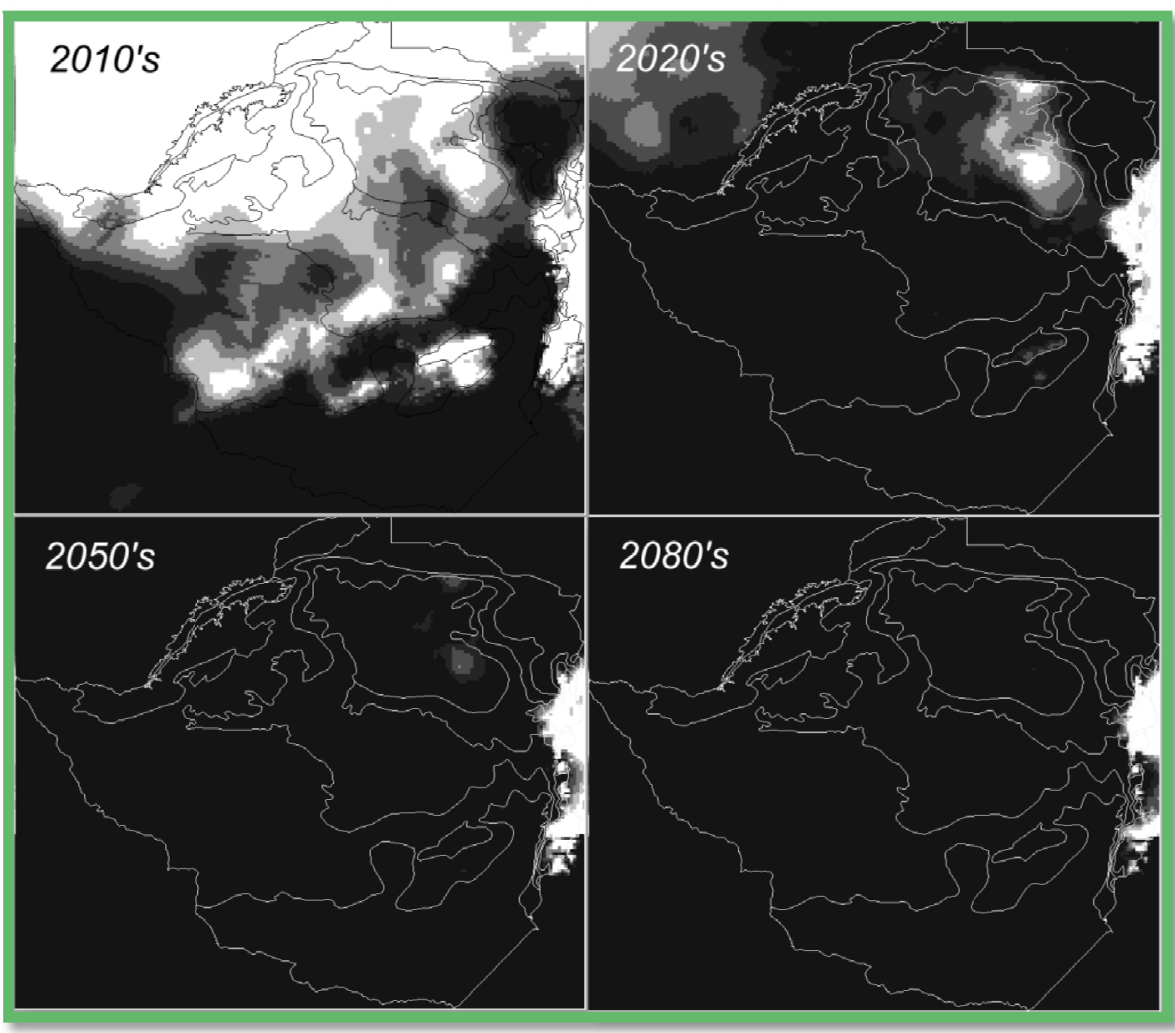

Figure 13. Map showing change in suitability of late maturing maize from current to 2080's

White indicates excellent suitability (80-100\%), light Grey represents Very suitable areas (60-80\%), medium Grey represents suitable areas (40-60\%), Grey represents marginal suitability (20- 40\%) while dark grey indicates areas with very marginal suitability between 0 and $20 \%$. 